


\section{Simone Osthoff}

\section{De musas a autoras: mulheres, arte e tecnologia no Brasil*}

palavras-chave: arte; mídia; feminismo; tecnologia

keywords: art; media; feminism; technology
Este artigo aborda tanto realizações pioneiras quanto trabalhos midiáticos contemporâneos criados por artistas brasileiras trabalhando com meios como a música eletroacústica, o neon, a holografia, o cinema, "quase cinema”, vídeo, fotografia, performance e instalação multimídia, mundos virtuais e o ativismo cultural on-line. Partindo de uma discussão sobre a questão controversa do gênero no Brasil, o artigo tece considerações sociais, estéticas e epistemológicas. Como regra geral, as artistas examinadas aqui não exploraram questões femininas como um projeto, nem estavam interessadas em teorias feministas per se. Não obstante, elas contribuíram para o avanço das artes midiáticas no Brasil. O recorte panorâmico deste artigo, apesar do grande número de artistas abordadas, não é de forma alguma uma análise completa, mas sim uma primeira avaliação que, esperamos, estimule a realização de futuras pesquisas.

This article surveys both pioneer accomplishments and contemporary works by Brazilian women media artists ranging from electro-acoustic music to neon light, holography, cinema, experimental film, video, photography, kinetic and multimedia performances and installations, virtual worlds, and Web-based cultural activism. It begins with a discussion of the controversial issue of gender in Brazil, weaving social, aesthetic, and epistemological concerns. As a general rule, the artists examined here did not explore women's issues as a project nor were they interested in feminist issues per se. Nevertheless, they contributed to the advancement of media arts in Brazil with critical feminine perspectives. This overview, despite the large number or artists, is by no means a complete survey, but rather a first assessment, which will hopefully instigate further research. 
* A primeira versão deste ensaio foi publicada sob o título: Brazilian counterparts: old histories and new designs. In: MALLOY, Judy (Ed.). Women, art and technology. Cambridge: MIT Press, 2003. Este artigo é a primeira tradução para o português da segunda versão bilíngue (inglês-francês), com o título: From muses to makers of media arts. In: BUREAUD, Annick (Ed.). ://Brasil. Paris: Anomos/Hyx, 2005.

Esta segunda versão expandiu o número de artistas de 17 para um total de 40 .

1. Gilda de Abreu citada em artigo da revista Manchete (sem data ou autor), reproduzido em HOLLANDA, Heloísa Buarque de (Org.). Quase catálogo 1: realizadoras de cinema no Brasil (1930-1988). Rio de Janeiro: CIEC/ Escola de Comunicação/ UFRJ;

MIS; Funarte, 1989, p. 100.

2. Sandra Kogut entrevistada pela autora, Rio de Janeiro, 10 ago. 1995.

3. Entre 1964 e meados dos anos 1980, o Brasil foi governado por uma ditadura militar. Em 13 de dezembro de 1968, o governo declarou o $\mathrm{Al}-5$ (Ato Institucional $n^{\circ} 5$ ), assinado pelo presidente, general Costa e Silva. 0 Al-5 fechou o Congresso e suspendeu todos os direitos políticos e constitucionais,
Eles [a equipe] me respeitavam mais quando eu estava de calças compridas do que quando usava saias. Acho que eles se sentiam diminuídos por serem dirigidos por uma mulher. Então eu tinha que usar calças compridas. Era uma coisa muito desagradável. Não a calça comprida, naturalmente, mas o fato de ter que parecer homem, para poder comandar.

Gilda de $\mathrm{Abreu}^{1}$, diretora do longa-metragem $\mathrm{O}$ ébrio, no qual estrelava o cantor popular Vicente Celestino, seu ma rido, um grande sucesso em 1946

Desde o início decidi que eu não ia falar grosso ou agir como homem no local de trabalho. Decidi que eu ia continuar usando minissaias, e que tudo deveria funcionar em função disso. E deu super certo. Com o tempo você vai aprendendo a falar de coisas pessoais e a usar isso no trabalho.

Sandra Kogut ${ }^{2}$, diretora de vídeo, cinema e TV, 1995

A transformação cultural dos anos 1960, documentada nas artes visuais, entre outros, pelo livro clássico de Lucy Lippard Six years: the dematerialization of the art object [Seis anos: a desmaterialização do objeto de arte], desafiou não apenas o status de mercadoria da arte, mas também o privilégio exclusivo dos autores como criadores inspirados. Realizada em geral em espaços públicos, grande parte da arte experimental dos anos 1960 desafiou também as convenções expositivas da arte no contexto das galerias, dos museus e do mercado da arte, pois o público era comumente convidado a participar da elaboração do significado das obras. A pintura expandiu-se para além da moldura e a escultura abandonou o pedestal, ao mesmo tempo que as fronteiras entre a arte e a vida praticamente desapareceram.

Os movimentos feministas e contraculturais dos anos 1960 fizeram parte desse ímpeto anti-hierárquico e igualitário que, no Brasil, assim como em outros países sul-americanos tais como Argentina, Uruguai e Chile, privilegiou o desafio a regimes opressores e às estruturas de classe, em vez das questões de gênero ${ }^{3}$. Apesar das questões de gênero nunca terem sido uma prioridade na agenda artístico-política, o número de artistas brasileiras tem se expandido continuamente nas últimas quatro décadas, como em outras partes do mundo, juntamente com a presença das mídias eletrônicas na arte contemporânea.

Até recentemente, as tentativas de fomentar organizações feministas no Brasil não floresceram, inclusive nas esferas acadêmicas das Artes, Humanidades e Ciências Sociais, onde as teorias feministas e homossexuais foram inicialmente vistas como uma importação norte-americana que não se aplicaria à "nossa realidade”. O cientista político Luiz E. Soares foi um 
abrindo o caminho para a perseguição política, a tortura e a censura que marcaram o final dos anos 1960 e principalmente o início dos anos

1970. A partir de 1979, o país voltou lentamente para a democracia e eleições presidenciais realizaram-se novamente em 1989.

4. Ver: SOARES, Luiz E. Consequências de uma antropologia trivial. Vitória:ABA -

Associação Brasileira de Antropologia, 8 abril 1998 lapresentação oral). Ver também: idem, Political correctness: the civilizing process in under way. In: Conferência internacional de filosofia analítica e pragmatismo. Belo Horizonte: UFMG, 6-8 ago. 1997 (apresentação oral).

Aqui Soares trabalhou com os números do censo de 1988 (PNAD), observando que o índice de analfabetismo na população com mais de

cinco anos era de $18 \%$ entre brancos e de $36,3 \%$ entre mulatos e negros. Em 1988, os salários eram muito desiguais (e continuam sendo): homens ganhando mais do dobro do salário de mulheres; homens brancos ganhando mais do dobro do salário de mulatos e negros; mulheres brancas ganhando mais do dobro do salário de mulatas e negras. Portanto, homens brancos ganhavam mais de três vezes o salário de mulheres negras. HASENBALG, Carlos; SILVA, Nelson.

Relações raciais no Brasil contemporâneo. Rio de Janeiro: Rio Fundo; IUPERJ, 1992. dos primeiros a chamar a atenção para a resistência brasileira às teorias feministas. Em 1997, Soares convocou um exorcismo dos esqueletos guardados nos armários das narrativas dominantes, por meio do foco em questões aparentemente mais triviais e micropolíticas para se abordar a macropolítica. Ele via, nas teorias feministas, o exame de questões epistemológicas fundamentais sobre autoria e sobre as relações entre sujeitos e seus discursos, em oposição à ênfase tradicionalmente dada à relação entre o discurso e seus objetos ${ }^{4}$.

Os teóricos que examinam os processos simbólicos de formação de identidades - tais como os conceitos de masculino e feminino, materno e paterno, os papéis de meninos e meninas - e portanto a influência da diferença sexual sobre as experiências sociais, psicológicas e epistemológicas do sujeito têm questionado a tradicional assexualidade da razão universal. Ao explorar o papel do corpo e da dimensão carnal da experiência humana, eles perguntam: há uma razão feminina? Uma estética feminina? Uma percepção feminina?5

Embora a misoginia, o racismo e a homofobia não sejam práticas sociais incomuns na América Latina, mesmo entre intelectuais progressistas, em geral não se considerava que essas questões devessem ser abordadas prioritariamente, ou mesmo separadamente daquelas concernentes às relações de classe e de raça. Um importante exame autocrítico das tendências autoritárias e chauvinistas entre a elite intelectual e política brasileira, a título de exemplo, foi realizado por Fernando Gabeira, ao retornar do exílio político na Suécia em $1979^{6}$. Entre as artistas que entrevistei para este artigo, o consenso geral parecia ser querer evitar o "gueto da estética feminina". As artistas brasileiras têm preferido falar de questões tais como o status de cidadãos de segunda classe que os artistas latino-americanos, infelizmente, ainda possuem na cena artística internacional. Lygia Pape expressou essa indignação: "Acho alarmante que ainda hoje uma exposição possa ser intitulada 'arte latino-americana'. Isso é discriminatório, além de ser muito redutor!”7

A primeira exposição cujo escopo eram as artistas brasileiras contemporâneas foi provavelmente "Ultramodern: the art of contemporary Brazil", apresentada em 1993 no The National Museum of Women in the Arts, em Washington D.C. No catálogo da exposição, a crítica de arte paulistana Aracy Amaral citou dois motivos para explicar por que algumas poucas mulheres artistas obtiveram proeminência no Brasil. Seus argumentos foram extremamente criticados na época e continuam a ser controversos ${ }^{8}$. Primeiro, ela assinalou que, nas culturas latinas, as artes sempre foram domínio das mulheres (o trabalho artesanal sendo domínio feminino, enquanto que os homens, envolvidos com os negócios, evitavam trabalhar com as mãos). Em segundo lugar, ela argumentou que as profissionais da 
5. Um exemplo nessa direção foi a criação, em 2001, do simpósio internacional As mulheres e a filosofia, organizado por, entre outras, Márcia Tiburi, na época professora de filosofia da

Universidade do Rio dos

Sinos, São Leopoldo, Rio Grande do Sul.

6. GABEIRA, Fernando. 0 que é isso, companheiro? Rio de Janeiro: Codecri, 1979; idem, 0 crepúsculo do macho. Rio de Janeiro: Codecri, 1980.

7. PAPE, Lygia. Entrevista a Lúcia Carneiro e lleana Pradilla. In: Lygia Pape. Rio de Janeiro: Nova Aguilar, 1998, p. 60.

8. AMARAL, Aracy. Brazil: women in the arts. In: Ultramodern: the art of contemporary

Brazil. Washington

D.C.: The National Museum of Women in the Arts, p. 17-33, 1993.

9. Idem, A propósito de um questionário de Sheila Leirner: existe uma arte especificamente feminina?. In: Arte e meio artístico: entre a feijoada e o x-burguer. São Paulo: Nobel, p. 254-256, 1983.

10. FREITAS, lole de. Entrevista a Ana Maria Machado (set. 1987). In: HOLLANDA, Heloísa

Buarque de (Org.).

Quase catálogo 2: artistas plásticas no Rio de Janeiro 1975-1985.

Rio de Janeiro: CIEC, 1991, p. 93. classe média brasileira têm sido capazes de administrar tanto a família quanto suas carreiras por causa da pronta disponibilidade de uma força de trabalho doméstica numerosa e barata.

Embora a primeira observação deAracyAmaral dificilmente possa ser comprovada, uma vez que muitos trabalhos artesanais costumam ser feitos por homens, acredito que sua segunda observação seja correta, e de importância fundamental. O desinteresse das artistas brasileiras com relação às questões de gênero pode ser pelo menos parcialmente explicado pelas estruturas de classe no país. No Brasil, a dupla jornada, que sobrepõe ao trabalho doméstico o trabalho profissional, é geralmente parte da realidade das mulheres mais pobres.

Embora reconhecendo que as relações de classe facilitam o acesso de mulheres de classe média e média-alta à força de trabalho, de um ponto de vista formal, as realidades sociais da desigualdade de gênero, segundo Amaral, não têm nada a ver com estética. Amaral falou em nome de muitas artistas brasileiras quando declarou que não acreditava na existência de uma estética feminina9 . A artista visual Iole de Freitas completa esse pensamento ao apontar: "Não sei por que ninguém procura pelo que é masculino na obra de um homem"10. Além disso, muitas concordaram com a diretora de cinema Suzana Amaral quando ela afirmou: "Não tenho paciência para reuniões do movimento feminista"11.

Entre as poucas exceções à falta de organizações políticas femininas citamos o Festival Internacional de Mulheres nas Artes, realizado em 1982, em São Paulo (3-12 de setembro), organizado por Ruth Escobar. Esse movimento feminista militante nas artes promoveu atividades em todas as áreas da cidade, com a exibição de outdoors com imagens e mensagens de artistas e uma demonstração pública com artistas portando cartazes nas ruas de São Paulo. Muito do ímpeto feminista do primeiro festival, porém, se dissipou lentamente, e os esforços para criar organizações feministas nas artes no Brasil entre 1975 e 1985 não floresceram. Não obstante, as perspectivas feministas tiveram uma presença relativa nos anos 1990, quando umas poucas artistas, curadoras e historiadoras da arte chamaram a atenção para o papel do gênero na cultura e na constituição de conceitos tais como o de subjetividade e "qualidade" artística, por exemplo, ao examinar a tradicional invisibilidade das mulheres na história da arte ${ }^{12}$.

Em uma entrevista em 2002, a musicista e artista performática multimídia Jocy de Oliveira ofereceu a seguinte opinião, quando questionada sobre a posição das mulheres na sociedade brasileira:

As coisas estão muito mais organizadas para as mulheres aqui do que há 30 anos atrás, com todas essas ONGs. Mas você pode se sentir 
11. AMARAL, Suzana, apud RAMOS, Carlos.

A vida começa aos 50 .

Tribuna da Imprensa, 29 abril 1986.

12. No Rio de Janeiro no final dos anos 1990, Alfredo Grieco, lole de

Freitas, Paula Terra, Márcia Rosefelt e Katie

Van Scherpenberg organizaram um ciclo de debates feministas sobre a história da arte no Museu da República. A artista Katie Van Scherpenberg, por exemplo, questionou o livro de Giulio Carlo Argan, A arte moderna, observando que "entre centenas de nomes, apenas seis mulheres são mencionadas. $\mathrm{E}$ este é um livro adotado como se fosse a Bíblia nas universidades brasileiras!".

13. OLIVEIRA, Jocy de. Entrevista a Tom Moore (ago. 2002). Disponível em: <musicabrasileira.org/ reviewsinterviews/jocy. html.>

14. A história da arte e tecnologia no Brasil, com exceção de alguns ensaios iniciais, começou a ser escrita na década de 1990 através da análise de obras que têm sido relegadas ao esquecimento e cujo valor, na maioria dos casos, só então se tornou aparente independentemente do gênero do artista.

Entre os projetos pioneiros está "A

radical intervention: the

Brazilian contribution to the international movement of electronic art", editado por Eduardo Kac para a revista Leonardo, e marginalizada como mulher em qualquer lugar, mesmo na Noruega. A questão do status das mulheres é algo que é pertinente para qualquer sociedade. Não sinto nenhuma discriminação, especialmente no Brasil - nunca senti. Mas isso é irrelevante. Outras sentiram isso, e a questão está aí. Se algumas mulheres não sentem, isso não faz nenhuma diferença - é a maioria que conta. ${ }^{13}$

A presença de duas mulheres fortes em movimentos de vanguarda no início do século XX exemplifica as observações de Oliveira. Como se sabe, o modernismo foi introduzido em São Paulo nas artes visuais, por exemplo, pela exposição de Anita Malfati em 1917 e pelos quadros de Tarsila do Amaral nos anos 1920, em diálogo com a poesia e a literatura do movimentoAntropofágico, que sintetizou os ideais do canibalismo cultural durante muitas décadas.

\section{Três pioneiras nos anos 1960}

Jocy de Oliveira, Sulamita Mairenes e Tereza Simões são três das primeiras visionárias das artes midiáticas que ainda esperam receber uma maior avaliação crítica e reconhecimento histórico ${ }^{14}$. Radicada no Rio de Janeiro, mas tendo passado grande parte da sua carreira nos EUA e na Europa, a compositora, pianista e autora multimídia Jocy de Oliveira tem trabalhado desde o início dos anos 1960 combinando instrumentos eletrônicos e acústicos, teatro, texto e imagem, em performances multimídia ${ }^{15}$. Como pianista, ela é conhecida por suas performances ao gravar a obra para piano de Messiaen. Foi também solista sob a batuta de Stravinsky e tocou nas principais orquestras dos EUA, da América do Sul e da Europa. Jocy de Oliveira estreou muitas peças de Xenakis, Berio, John Cage e Santoro, entre outros, incluindo algumas dedicadas a ela. Por quatro décadas a artista explorou uma ampla gama de trabalhos multidimensionais e multissensoriais. Como autora escreveu peças para voz, instrumentos acústicos e eletrônicos, elementos visuais, movimento, áudio e videoteipe, para dançarinos e para ações urbanas site-specific, com obras geralmente colaborativas e criadas especificamente para certos espaços ${ }^{16}$.

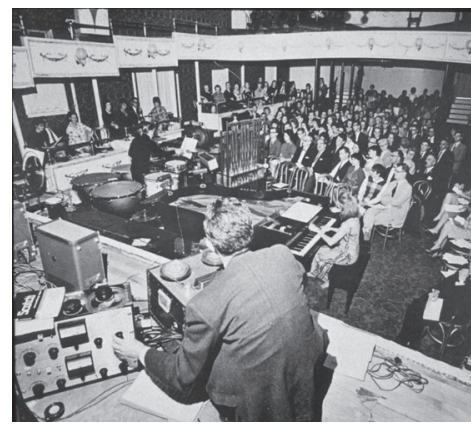

Jocy de Oliveira na performance Winter Music de John Cage em um navio-teatro no rio Mississippi, 1964. Dez pianos foram colocados em vários pontos do navio para executar a peça. Foto: James Rackwittz, cortesia da artista. 
começando com o v. 29, n. 2, 1996. No Brasil, com exceção de alguns artigos isolados escritos por Mario Pedrosa,

Walter Zanini e outros, a primeira exploração mais aprofundada da arte eletrônica foi realizada por Arlindo Machado em $A$ arte do vídeo. São Paulo: Brasiliense, 1988, seguida por outras publicações de Machado,

entre outros autores.

Entre as primeiras autoras de livros sobre as novas mídias estão Lúcia Santaella, Diana

Domingues, Maria Beatriz de Medeiros e

Suzete Venturelli. Para um relato conciso do início da história da arte e tecnologia no Brasil, ver também ZANINI, Walter.

Primeiros tempos da arte/tecnologia no Brasil. In: DOMINGUES, Diana (Org.). A arte no século XXI: a humanização das tecnologias. São Paulo:

Fundação Editora da UNESP, p. 233-242,1997.

15. OLIVEIRA, Jocy de. Days and routes through maps and scores. Rio de Janeiro:

Record, 1984; idem, Apague meu spotlight.

São Paulo: Massao

Ohno, 1961; idem, $3^{\circ}$

Mundo. São Paulo:

Melhoramentos, s/d.

16. «www.jocydeoliveira. com>

17. MORAIS, Frederico de. Oráculos e hologramas no teatro de objetos de Sulamita Mairenes. 0 Globo, Rio de Janeiro, 23 maio 1984.
Outra pioneira da década de 1960, radicada em São Paulo, é a artista Sulamita Mairenes. Sua trajetória, bem menos documentada, explorou uma abordagem psicológica de mídias eletrônicas e óticas. Na IX Bienal Internacional de São Paulo, em 1967, Sulamita apresentou Objetos parapsicológicos eletrônicos e, em 1980, foi uma das artistas pioneiras no trabalho com hologramas ${ }^{17}$.

A luz é um dos meios da arte eletrônica que ainda não foram suficientemente explorados no Brasil. O crédito da mais antiga tentativa no país de usar neon como o principal material para escultura costuma ser dado a Tereza Simões, que, no início dos anos 1970, encontrou muita resistência entre críticos, curadores e colecionadores ${ }^{18}$. Uma exploração mais vasta da luz como meio foi desenvolvida a partir de 1990, pela artista paulistana Ana Barros, por exemplo.

\section{Cinema: na frente e atrás das câmeras}

Se é raro encontrar mulheres entre os diretores de filmes comerciais anteriores aos anos 1970, elas estão completamente ausentes da direção nos principais movimentos de vanguarda do cinema brasileiro. Desde o memorável filme de Mário Peixoto, Limite, de 1930, e durante o movimento do Cinema Novo no início dos anos 1960, assim como no movimento underground da "Estética do Lixo" no final dos anos 1960, o território de vanguarda do cinema nacional tem sido dominado exclusivamente pelos homens. As mulheres começam a contribuir como autoras e diretoras somente no contexto da experimentação nas artes visuais, com formatos de filmes variando de super-8 a 16 mm, 35mm e vídeo, nas décadas de 1960 e 1970.

Entre 1930 e 1988, 195 diretoras de cinema produziram 479 filmes, em sua maioria curtas-metragens e documentários ${ }^{19}$. Em 1982, Elice Munerato e Maria Helena Darcy de Oliveira analisaram, no livro As musas da matinê, os longas-metragens de ficção feitos por mulheres existentes no Brasil até 1979: havia somente vinte filmes! Dentre aqueles filmes, elas conseguiram projetar somente dezesseis. Quatro não sobreviveram ao tempo. Suas conclusões, de certo modo alarmantes, diziam que, embora fosse possível falar de um crescente número de mulheres diretoras de cinema nos anos 1970, os filmes mais recentes continuavam a reforçar antigos estereótipos ${ }^{20}$.

Muito tem mudado na indústria do cinema desde o estudo de Munerato e Oliveira em 1982. Após a falência quase completa da indústria de cinema nacional nos anos 1980, a década seguinte viu um aumento na produção nacional e um relativo sucesso comercial dos longas-metragens dirigidos por mulheres. Entre as veteranas e novas diretoras que contribuíram para fortalecer a indústria de cinema 
18. SIMÕES, Teresa. Entrevista a Helena

Salem (out. 1987). In:

HOLLANDA (Org.), op. cit., p. 101, 1991.

19. PESSOA, Ana; MENDONÇA, Ana Rita. Por trás das câmeras. In: HOLLANDA (Org.), op. cit., p. 7-16, 1989.

20. MUNERATO, Elice; OLIVEIRA, Maria Helena Darcy de. As musas da matinê. Rio de Janeiro: Rioarte, 1982.

21. "Quase cinema" é uma expressão cunhada por Hélio

Oiticica, em referência às suas experiências com som e imagens em movimento. Hoje ela se refere a toda produção audiovisual experimental nas artes visuais nos anos 1960 e 70 . Veja também: BASUALDO,

Carlos. Hélio Oiticica quasi cinemas.

Kunstverein Kölnischer; New Museum of

Contemporary Art;

Wexner Center for

the Arts; Hatje Cantz, 2001; CANONGIA, Ligia.

Quase cinema. Caderno de textos $n^{0} 2$, Rio de Janeiro, Funarte, 1981.

22. Desenvolvi esse argumento no ensaio: Lygia Clark and Hélio Oiticica: a legacy of interactivity and participation for a telematic future.

Leonardo, v. 30, n. 4, p. 279-289, 1997.

23. PAPE, Lygia, apud CANONGIA, op. cit., p. $43-44$ nacional estão: Norma Benguel, Ana Maria Magalhães, Ana Carolina, Tizuka Yamasaki, Sandra Werneck, Tereza Trautman, Susana Moraes, Helena Solberg, Carla Camurati, Flávia Moraes e Daniela Thomas.

\section{“Quase cinema": a imagem em movimento nas artes visuais}

Os experimentos com os formatos super-8, $16 \mathrm{~mm}, 35 \mathrm{~mm}$ e vídeo nas artes visuais nos anos 1960 e início dos anos 1970 se tornaram conhecidos como "quase cinema" ${ }^{21}$. Resultando da ênfase no processo mais que no produto acabado nos anos 1960, esses filmes documentavam um grande número de ações conceituais, performances e happenings. Ao trazer o tempo para o espaço das artes visuais, a vanguarda dessas décadas geralmente acrescentava, àquelas considerações experimentais, atitudes críticas com relação ao cinema comercial. Entre as artistas que exploraram filme e vídeo no Rio de Janeiro, estavam: Lygia Pape, Anna Bella Geiger, Iole de Freitas, Sônia Andrade, Miriam Danowsky, Letícia Parente e Regina Vater (trabalhando nos EUA desde o início dos anos 1970); em São Paulo: Carmela Gross e Regina Silveira. As trajetórias dessas artistas, similares às propostas conceituais de Lygia Clark, estão enraizadas nas novas direções da arte nos anos 1960: de obras baseadas no objeto às experiências centradas no corpo, do material ao imaterial e de processos mais inflexíveis aos mais maleáveis. A obra de Clark, por exemplo, abriu caminhos conceituais para práticas mais fluidas, intangíveis e baseadas em software, que seriam relevantes para a próxima geração de artistas trabalhando com novas mídias ${ }^{22}$. Essa produção experimental de filmes e vídeos em geral ficou limitada ao circuito das artes visuais e, com poucas exceções, não teve continuidade. Seu público era pequeno, e somente na era da videoinstalação ela está atraindo o interesse de expectadores seletos e de historiadores e críticos de arte.

Lygia Pape (1927-2004), participante do grupo Neoconcreto do Rio de Janeiro (1959-1963), trabalhou com o grupo do Cinema Novo, fazendo anúncios, pôsteres e design gráfico. Ela era crítica à "redução à escala do tempo comercial" que frequentemente testemunhava no trabalho dos diretores do Cinema Novo. Referia-se a ela como um processo de castração: a edição, a limpeza do material bruto em nome do gosto médio exigido pelas bilheterias, o acréscimo de música descritiva e diálogos tolos ${ }^{23}$. A filmografia de Pape vai do didático ao humorístico, incluindo ambos os gêneros, ficção e documentário, em um total de doze curtas-metragens feitos entre 1963 e 1982, cada um com uma estrutura diferente. O processo de edição de Eat me, por exemplo, é determinado pelo sistema métrico. $\mathrm{O}$ ritmo da edição segue a lógica da divisão: primeiro dois metros de filme, depois um metro, 1/2 metro, 25 
24. Sobre Geiger, ver, entre outros: COCCHIARALE,

Fernando. Anna

Bella Geiger. Rio de Janeiro: Funarte, 1978; COCCHIARALE, F.; INTERLENGHI, Luíza. Anna Bella Geiger: constelações. Rio de Janeiro: Museu de Arte Moderna do Rio de Janeiro, 1996.

25. CANONGIA, op. cit., e também o catálogo Precursores e pioneiros

contemporâneos. Curadoria de Vitória Daniela Bousso. São Paulo: Paço das Artes. 1977.

Iole de Freitas, Glass peças/vida slices, 16 mm, 1974, a artista fragmentou imagens do seu corpo empregando um grande número de pequenos espelhos.

Fotos: cortesia da artista. cm e assim por diante, em uma aceleração crescente de cortes, numa tentativa de romper com os parâmetros da montagem tradicional.

Como Pape, Anna Bella Geiger era uma artista reconhecida quando se tornou uma precursora da videoarte no anos 1970. O vídeo Passagens (p\&b, 12 minutos) feito por Geiger em 1974, atualmente na coleção do Museu de Arte Moderna de Nova Iorque, descreve um espaço virtual a partir de uma série de degraus em "loop" que a artista ascende indefinidamente, descrevendo trajetórias retilíneas, em zig-zag e diagonais. No vídeo Mapas elementares, de 1977, Geiger desenha um mapa da América Latina, usando cópia e frottage, em tempo real. Aqui, questões de topologia e tempo assumem um significado estético-político. Geiger continua suas investigações geopolíticas atualmente na série Local da ação - desenhos e gravuras bidimensionais, assim como objetos e instalações multimídia onde mapas e palavras criam cartografias, tanto formais quanto conceituais, que questionam o lugar da artista no mundo e na história da arte ${ }^{24}$.

Explorando seu próprio corpo com a mobilidade da câmera super-8, Iole de Freitas criou, no início dos anos 1970, narrativas visuais em torno do "eu". Seu primeiro filme, intitulado Elementos, de 1972, foi feito no formato super-8. É uma narrativa visual sobre a natureza material de elementos tais como água, mercúrio e a própria pele, enfatizados através da natureza material do filme - luz e granulação - e moldados pelas lentes da câmera em variações de foco, profundidade e "close-ups". No filme seguinte, Glass peças/vida slices, em $16 \mathrm{~mm}$, de 1974, a artista fragmentou imagens de si mesma empregando um grande número de pequenos espelhos. Freitas usou as partes para chegar ao todo, justapondo reflexões do "eu" 25 .

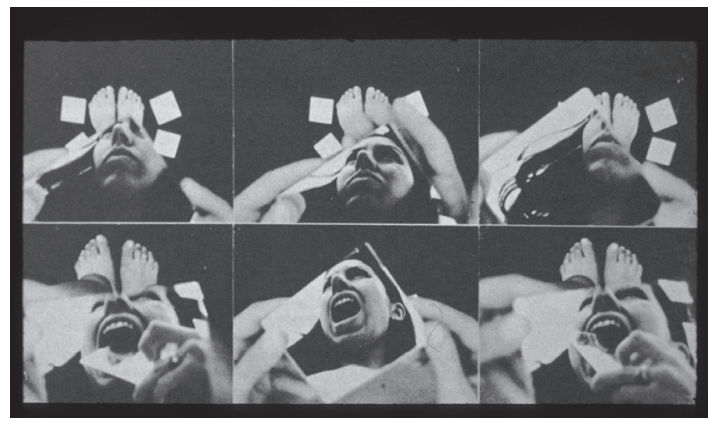

As investigações conceituais de Regina Silveira sobre a natureza da arte e da representação empregaram uma ampla gama de mídias - de gravuras a instalações com painéis LED, lasers e outros meios. Entre 1977 e 1981, Silveira produziu sete vídeos de curta duração. A arte de desenhar, p\&b, de 2’23" de duração, feito em 1978, fazia parte de uma série de trabalhos com o mesmo título incluindo gravuras, desenhos, fotocópias, livros de artista e um 
26. Entre outros, ver MORAES, Angélica de (Org.). Regina Silveira: cartografias da sombra. São Paulo: EDUSP, 1996. «www.uol.com.br/ reginasilveira>

27. Sobre a história da videoarte no Brasil, ver: MACHADO, Arlindo. Video art: the Brazilian adventure. Leonardo, v. 29 , n. 3, p. 225-231, 1996 ; idem, A experiência do vídeo no Brasil. In: Máquina e imaginário. São Paulo: EDUSP, p. 253-274, 1993; idem (Org.), Made in Brasil: três décadas do vídeo brasileiro. São Paulo: Itaú Cultural, 2003.

Sandra Kogut, Parabolic People, vídeo, 45 minutos, 1991 é uma colagem de filmagens feitas nas ruas de Dakar, Moscou, Nova York, Tóquio, Paris, e Rio de Janeiro. Editado digitalmente, o vídeo é falado e escrito em pelo menos quatro línguas. sem tradução. Fotos: cortesia da artista. vídeo, que questionava a destreza manual e o trabalho artístico enfatizando operações mais experimentais e conceituais ${ }^{26}$.

\section{Videoarte para exportação: a arte eletrônica avança}

A explosão da videoarte no Brasil nos anos 1980 aponta para uma segunda geração de artistas interessadas nesse meio ${ }^{27}$. Uma das características dessa segunda geração de artistas de vídeo foi a subversão da linguagem da TV a partir de dentro. Para essas artistas de vídeo independentes, a televisão era uma referência fundamental. Sua abordagem contrastava com aquela da primeira geração de artistas de vídeo, que via a televisão - estruturada pela publicidade como superficial, intelectualmente vazia, enfim, como uma arma na manipulação capitalista dos consumidores.

Sandra Kogut começou a trabalhar com vídeo nesse contexto no Rio de Janeiro dos anos 1980, mas ajudou a definir a terceira geração de artistas trabalhando com vídeo, que alcançou reconhecimento internacional no início dos anos 1990. Após a experiência pública e participativa de suas cabines de vídeo instaladas nas ruas do Rio de Janeiro - Videocabines são caixas pretas, 9 minutos, 1990 -, Kogut expandiu o projeto para outras cidades do mundo. Seu próximo vídeo, intitulado Parabolic people, é uma colagem de 41 minutos de filmagens feitas nas ruas de Dakar, Moscou, Nova Iorque, Tóquio, Paris e Rio de Janeiro. Esse vídeo, falado em muitas línguas e sem tradução, refletiu sua filosofia e processo de trabalho em camadas, explorados com sucesso em sofisticada edição digital. O sincretismo de Kogut celebra os elementos urbanos altamente contrastantes das colagens cada vez mais rápidas que experimentamos como flaneurs supermodernos.

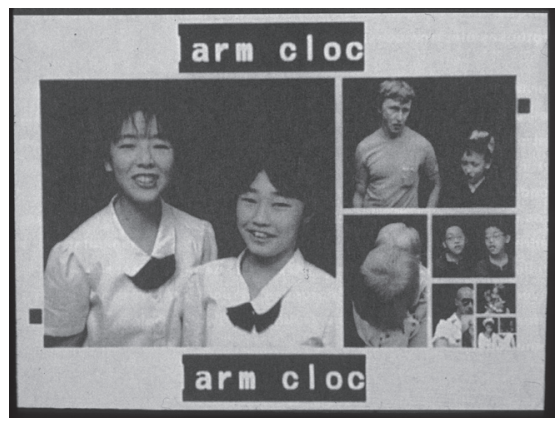

Fotografia, memória e história: os arquivos universais de Rosângela Rennó 
30. Nelson Rodrigues

(1912-1980) nasceu

em Recife, viveu e

trabalhou no Rio de

Janeiro. Foi jornalista

e escritor de crônicas,

contos, romances e

peças, e um autor

altamente controverso

- amado e odiado com

a mesma intensidade.

Era considerado um

gênio e um louco,

um reacionário e um

revolucionário. Sua obra

foi republicada pela

Companhia das Letras.

Ruy Castro escreveu

uma biografia de Nelson

Rodrigues em $\mathrm{O}$ anjo

pornográfico. Rio de

Janeiro: Companhia das

Letras, 1992.

28. Entre outros, ver

Rosângela Rennó. São

Paulo: EDUSP, 1997;

MACHADO, Arlindo.

Camera obscura. World

Art, 4/1990; Rosângela

Rennó: cicatriz. Catálogo

de exposição organizada

por Alma Ruiz. Los

Angeles: Museum of

Contemporary Art, 1996.

Esquerda: Rosângela

Rennó, 2 Cruzes, da

série Cicatriz, Museu

Penitenciário, 1997/98.

Direita: Rosângela

Rennó, 3 Buracos,

1998, da série Vulgo,

Museu Penitenciário.

Fotos: cortesia da

artista.
Como outras grandes cidades do mundo, Rio de Janeiro e São Paulo são uma mistura de realidades e culturas distintas, com agudos contrastes sociais e econômicos. Na América Latina essas disparidades são ainda mais acentuadas pelos profundos problemas sociais, a violência e a péssima infraestrutura urbana, desafios que coexistem lado a lado com a presença ostensiva de novas tecnologias associadas a modas e tendências cosmopolitas. Esses contrastes produzem justaposições surpreendentes que são tão problemáticas quanto carregadas de energia criativa.

As disparidades urbanas são o terreno comum do fotojornalismo, que expõe injustiças sociais, violência e miséria, geralmente lhes conferindo um valor estético e, ao mesmo tempo, de choque e espetáculo. Rosângela Rennó, artista de Belo Horizonte radicada no Rio de Janeiro, subverte a pretensão objetiva da fotografia ao examinar o meio de forma crítica, expandindo suas possibilidades materiais, formais e conceituais e questionando conceitos como apropriação, originalidade, memória, identidade e igualdade. Em 1985, Rennó começou a usar imagens fotográficas encontradas em arquivos familiares, e mais tarde em arquivos públicos. Ela enfatizava a materialidade do meio, a degeneração dos negativos, a passagem do tempo, fazendo, ao mesmo tempo, observações agudas sobre laços familiares e a vida social, cultural e política nos grandes centros urbanos. Desde o início a artista vem explorando a tensão entre palavras e imagens ao justapor fotografia, títulos e textos tirados do seu "arquivo universal", i.e., artigos publicados em revistas e jornais de que ela se apropria e recombina. Por duas décadas Rennó empregou uma linguagem poética complexa e sutil para tratar de questões carregadas de violência política. Através do uso de imagens às vezes somadas somente ao texto, mas geralmente também relacionadas ao espaço expositivo, suas instalações questionam as condições sob as quais o significado é produzido: de quem são as memórias preservadas nos arquivos? Quais memórias chegam a ser materializadas em forma e espaço ${ }^{28}$
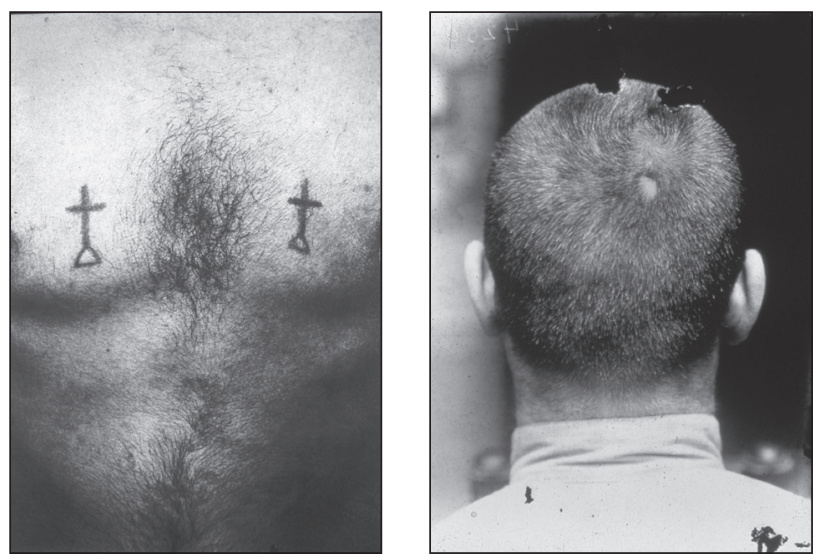


\section{Objetos eletrônicos de Márcia X: baixa tecnologia e alto impacto}

29. BASBAUM, Ricardo. "X": percursos de alguém além de equações. Concinnitas, Rio de Janeiro, Instituto de Artes da Universidade do Rio de Janeiro, n. 4, mar. 2003.

Esquerda: Márcia $X$ da série Fábrica Fallus, 1993-2000. Direita: Márcia X, Os Kaminhas Sutrinhas, 1995. Instalação com vinte e oito camas (cada uma com $17 \times 30$ $x 22 \mathrm{~cm}$ ) com bonecas eletrônicas conectadas uma às outras. Fotos:

Vicente de Mello, cortesia da artista.
Os múltiplos e as cópias, temas que fazem parte da fotografia, estão também presentes nos movimentos repetitivos dos objetos e instalações da artista performática Márcia X (1959-2005), do Rio de Janeiro. Ao avaliar as duas décadas da sua presença na cena artística do Rio, Ricardo Basbaum assinalou a originalidade com que suas performances romperam com as expectativas do comportamento artístico bem-sucedido dos anos 1980, desafiando a caracterização dessa geração como composta essencialmente de pintores neo-expressionistas ${ }^{29}$.

Algumas de suas performances no final dos anos 1980 envolviam objetos e instalações que, em meados dos anos 1990, constituíram um inesquecível corpo de obras feitas com brinquedos eletrônicos e objetos de sex shops. A instalação Kaminhas Sutrinhas, de 1995, é um exemplo. Uma fusão eletromecânica de brinquedos infantis, essa instalação bem-humorada produz, ao mesmo tempo, significados conceituais, formais e espirituais. Kaminhas Sutrinhas, que lembra um berçário enlouquecido, é uma instalação feita de um grande número de camas de bonecas belamente decoradas, nas quais bebês eletrônicos sem cabeça formam casais ou pequenos grupos conectados uns aos outros e fazendo amor incansavelmente, de acordo com as posições do Kama Sutra. A obra de Márcia X ecoa a irreverência das máquinas disfuncionais de Jean Tinguely e também as metáforas mecânicas sexuais de Duchamp e Picabia, além de fazer referência às tradições iconográficas do catolicismo, das religiões afro-brasileiras e do hinduísmo. Combinando o sagrado e o profano, infância e sexo, a artista dissolve as fronteiras entre formas passivas e agressivas, atributos masculinos e femininos, pornografia e arte. Fábrica fallus, iniciada em 1993, é uma série feita com vários tipos de vibradores eletrônicos de sex shop, na qual essas formas fálicas são travestidas e caracterizadas de acordo com diversos papéis, trocando de gênero e de identidade, de forma espirituosa e sutilmente subversiva.
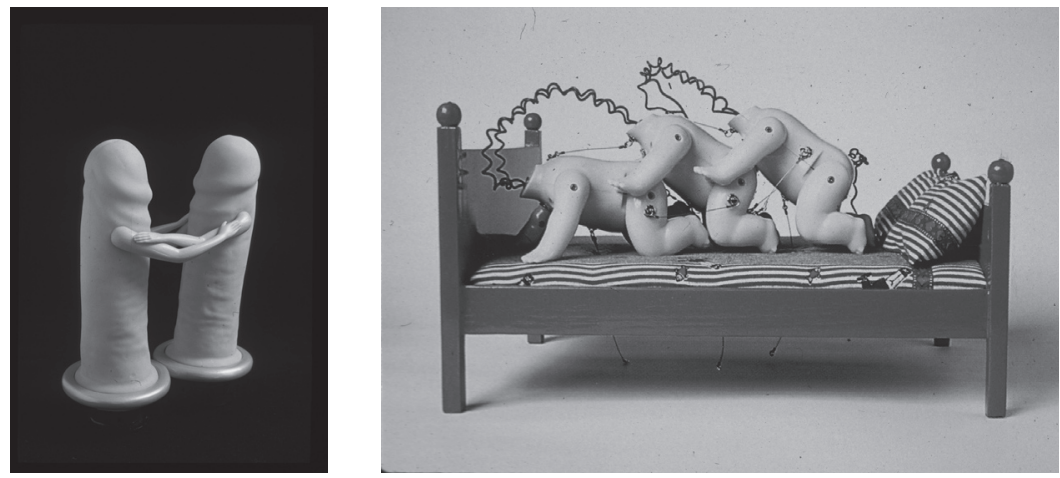

Simone Osthoff De musas a autoras: mulheres, arte e tecnologia no Brasil 
31. BESSA, Sérgio.

X-Rated. Item-4, Rio de

Janeiro, p. 79-83, nov. 1996

32. Entrevista à autora, Rio de Janeiro, 18 ago. 1998.
O crítico de arte Sérgio Bessa observou que, assim como o controverso autor carioca Nelson Rodrigues, Márcia X explora os paradoxos da classe média brasileira, com suas ambiguidades espirituais, sociais e sexuais, de forma direta e "anti-hipócrita" ${ }^{30}$. Bessa explica:

O fato novo é que esse papel de intelectual moralista tem sido um privilégio masculino. Na cultura brasileira o papel das mulheres tem sido continuamente delegado à área do "poético"; em termos gerais, uma mulher consegue optar entre ser "musa" ou artista frágil, "intuitiva". Raramente, no discurso cultural brasileiro, há a oportunidade de se ouvir uma voz crítica feminina. Essa inversão de valores é de importância vital na obra de Márcia X. ${ }^{31}$

Márcia X falou de seu interesse nessa tecnologia popular:

No Rio de Janeiro tem havido recentemente uma invasão de produtos eletrônicos chineses baratos, imitações da Barbie, brinquedos que falam inglês e toda sorte de aparelhos com som e movimento. As calçadas do Rio foram tomadas pelos vendedores de rua, que vendem todo tipo de produtos eletrônicos importados e baratos, montados no Paraguai ou na China. Essa economia globalizada não era tão aparente até recentemente. ${ }^{32}$

Usando o que ela chama de "tecnologia de Punta del Leste", Márcia cria um irônico trocadilho com a noção de progresso implícita na expressão "tecnologia de ponta"; uma expressão imediatamente diminuída por sua associação com uma indústria de cópias baratas. Um lugar que centraliza esse tipo de comércio no centro do Rio é a área conhecida como Sahara, onde os lojistas são tradicionalmente de origem árabe. O humor e o erotismo do trabalho de Márcia X sugerem uma inversão carnavalesca dos papéis sociais masculino e feminino, fazendo, ao mesmo tempo, referências sutis ao panteão espiritual brasileiro. Seus trabalhos costumam atrair vários tipos de público ao combinar cultura popular e crítica cultural.

\section{Performances e instalações multimídia a partir do anos 1990}

Artemis Moroni começou a desenvolver ambientes robóticos multimídia interativos com o grupo * * (asterisco ponto asterisco) em 1989. Ela trouxe para as artes visuais uma experiência vinda da área da informática. Enquanto trabalhava no Instituto de Automação do CTI (Fundação Centro Tecnológico para a Informática), Moroni, colaborando com outros membros do grupo, criou, em 1992, Variações previstas, obra apresentada na XXI Bienal Internacional de São Paulo. Essa instalação robótica interativa era uma coreografia multimídia empregando um robô Puma, dez aparelhos de TV, um videocassete, uma câmera VHS, computadores, sintetizadores, alto- 
33. MEDEIROS, Bia.

Da atualidade da linguagem artística da performance. In: TEIXEIRA, João Gabriel

L. (Ed.). Performáticos, performance \& sociedade. Brasília: Editora Universidade de Brasília, p. 71-73, 1996.

Simone Michelin, Zona Polisensorial. N.1, 16 de dezembro de 1997, instalação de vídeo realizada no salão de entrada do prédio da reitoria da Universidade Federal do Rio de JaneiroUFRJ. Fotos: cortesia da artista.

falantes e um PC (controlador programável).

O robô foi programado para desenhar no espaço, e seus movimentos e coreografias eram sincronizados com músicas para criar seu repertório: Slow (quatro minutos), Cumbica (referência ao aeroporto internacional de São Paulo, que sugere o movimento do voo), Realejo e Baleia (coreografia de nove minutos que explora a liquidez da água). Dançarinos acompanhavam o robô. Suas imagens eram apresentadas simultaneamente em vários monitores, criando um jogo de pontos de vista em imagens teatrais mediadas eletronicamente. O robô foi empregado como um aparelho artístico e lúdico - um improvável parceiro de dança que atuava graciosamente nesse ambiente interativo.

Em 1997, Moroni e o grupo ** criaram AtoContAto, uma performance de dança sônica-visual que usava uma interface gestual projetada por Jonatas Manzolli especialmente para esse projeto. $\mathrm{O}(\mathrm{a})$ dançarino(a), através dos sensores piezoelétricos colocados embaixo de seus sapatos, controla a performance, criando movimentos livres que geram mudanças no material sonoro através de mensagens MIDI. Os dançarinos também interagem com imagens de vídeo em tempo real, onde os corpos virtuais dançam com os corpos reais no palco. Os dançarinos se tornam um novo instrumento musical feito das interações homem/computador, que aumenta as conexões entre imagem, som e ritmo.

Radicada no Rio de Janeiro, a artista multimídia gaúcha Simone Michelin tem explorado a linguagem do vídeo em instalações tanto no espaço de galerias quanto em ambientes públicos. A obra de Michelin está enraizada no experimentalismo do final dos anos 1970 que emergiu dos grupos "Nervo Ótico" e "Espaço N.O." na cidade de Porto Alegre. Entre suas instalações multimídia está a intervenção crítica no campus universitário intitulada Zona polissensorial n. 1, realizada em 16 de dezembro de 1997.

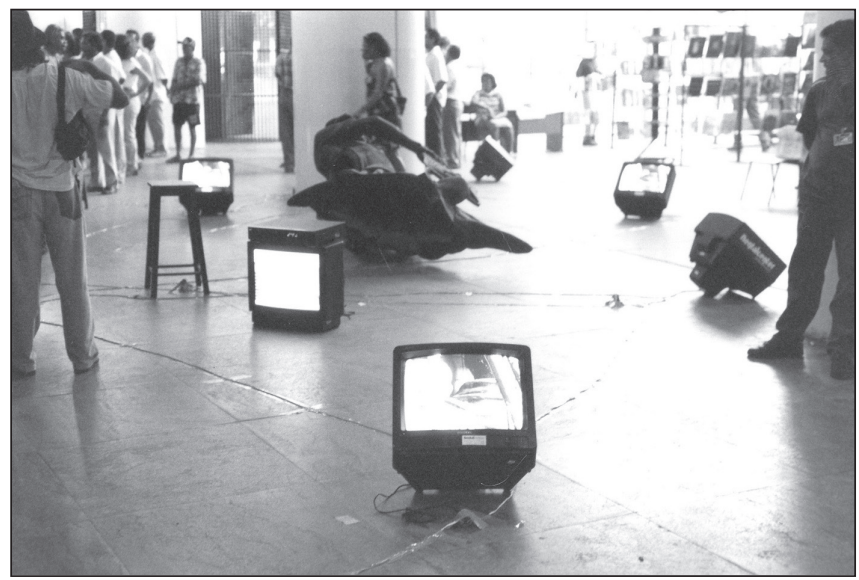


Essa intervenção pública foi realizada no salão de entrada do prédio da reitoria da Universidade Federal do Rio de Janeiro/UFRJ, que também hospedava a Escola de Belas-Artes e a Escola de Arquitetura. O trabalho enfatiza a produção artística e crítica na universidade como parte de uma rede ampliada de instituições artísticas. Essa área de grande tráfego de pessoas tornou-se uma corrida de obstáculos, ocupada por uma estátua quebrada do século XIX colocada sobre um pequeno carrinho de quatro rodas e cercada por sete monitores de TV alinhados em ângulos de 45 graus no chão. Três canais de vídeo exibiam imagens dos depósitos da universidade cheios de móveis quebrados e abandonados, juntamente com fragmentos de dissertações e teses e medalhas comemorativas com efígies de presidentes brasileiros. Essa intervenção no fluxo rotineiro da universidade foi uma reflexão alegórica sobre o lugar da arte naquela instituição federal - um sistema educacional complexo em permanente estado de crise.

Empregando vídeo em grandes performances de grupo que exploram as fronteiras entre o corpo e a tecnologia, Bia Medeiros coordena o grupo de pesquisa em multimídia GPCI - Grupo de Pesquisa Corpos Informáticos -, radicado em Brasília. Adotando uma abordagem crítica e às vezes de confronto com a arte performática, Medeiros explora o espaço onde corpos pulsantes e vivos e tecnologias eletrônicas se encontram. Seus eventos sensoriais e telepresentes criam novas ecologias onde o corpo, imagens de vídeo e redes digitais interagem e coexistem ${ }^{33}$.

Artista, professora, editora e curadora veterana de simpósios e festivais internacionais de arte eletrônica, Diana Domingues tem realizado inúmeras exposições, tanto no Brasil quanto no exterior, colaborando geralmente com especialistas de várias áreas. Assim como Simone Michelin, a artista começou a explorar novas mídias no final dos anos 1970, como participante do grupo de artistas experimentais do "Espaço N.O.", na cidade de Porto Alegre. Mais conhecida por seus ambientes interativos, Domingues desenvolveu uma reputação no Brasil fora do eixo Rio de Janeiro-São Paulo. Sua exposição interativa de 1995, Trans-e, era composta de quatro grandes ambientes onde aspectos do interior do corpo eram revelados em fluxo pulsante, em oposição às imagens estáticas de órgãos nos livros de anatomia. Nesse trabalho, Domingues empregou várias tecnologias para interagir com a presença física do público: câmeras de vídeo para registrar a presença do visitante; amplificadores para ecoar suas vozes; líquidos que se movem e pingam acionados pelo movimento dos

34. Leonardo, v. 30 n. 4,1997, p. 254 corpos na galeria, que, registrados por sensores infravermelho, proporcionam às máquinas funções orgânicas. Essa viagem pelo interior do corpo também envolve imagens captadas por microcâmeras ${ }^{34}$. 


\section{Mundos virtuais e on-line}

35. POPPER, Frank. Art of the electronic age. Nova lorque: Thames and Hudson, 1993, p. 180.

\section{FRAGA, Tânia. Simulações estereoscópicas interativas. In: DOMINGUES (Org.), op. cit., p. 117-125.}

Tânia Fraga, Simulações Estereoscópicas Interativas, 1992-93. Fotos: cortesia da artista.
Contrastando com o jogo entre presença e ausência, espaços físicos e virtuais das performances e instalações deArtemis Moroni, Simone Michelin, Bia Medeiros e Diana Domingues, os trabalhos de Tânia Fraga, Rejane Spitz, Suzete Venturelli, Giselle Beiguelman e Patrícia Canetti exploram mundos virtuais, o design, a arte e o ativismo on-line, respectivamente. Os mundos virtuais de Tânia Fraga são feitos para a tela do computador ${ }^{35}$ - Livres de restrições físicas, suas Simulações estereoscópicas interativas, criadas em 1992-93, desafiam a percepção dos expectadores com novas formas geométricas em movimento: ao mesmo tempo matematicamente lógicas e aleatórias, construtivas e surpreendentemente sensuais. Interessada nas possibilidades inexploradas das formas tridimensionais no espaço virtual - livres da gravidade e das leis da Física -, a artista desafia nossa percepção visual "natural", lembrando aos expectadores que a visão também é ideológica e culturalmente construída. Nossa maneira de representar formas tridimensionais no espaço bidimensional baseia-se nas noções de profundidade herdadas da perspectiva renascentista e reforçadas pelas lentes das câmeras fotográficas, do cinema e do vídeo. Esta, no entanto, é uma entre outras maneiras de representar a profundidade. As Simulações estereoscópicas interativas de Fraga exploram a percepção dos espaços virtuais dos usuários com sua lógica de movimento própria e comportamento inesperado ${ }^{36}$.

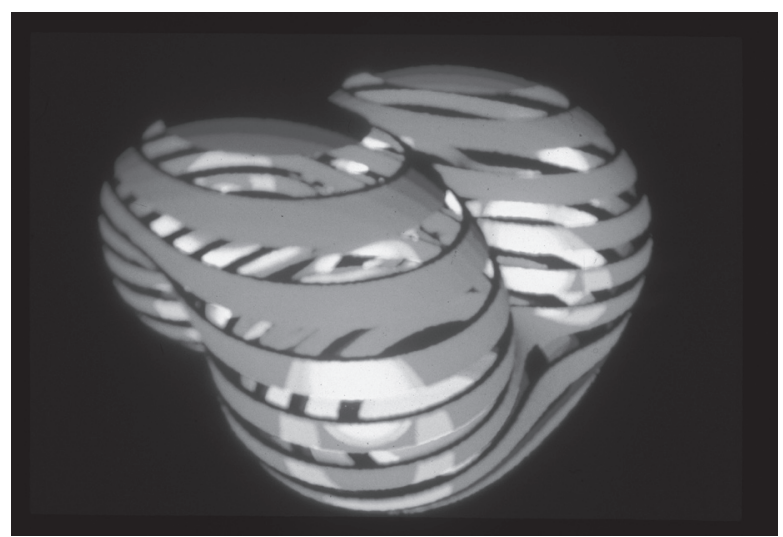

Tendemos a ignorar as perdas culturais geradas pelo progresso tecnológico. A destruição cultural por trás da criação é em parte o tema do trabalho de Rejane Spitz Private domain (please, keep off!). Artista, curadora, diretora de arte e uma das pioneiras no uso da tecnologia digital na área de design gráfico no Brasil, Spitz também atua internacionalmente, por exemplo, 
37. Leonardo, v. 30, n. 4, 1997, p. 254. como representante sul-americana da Siggraph e membro do comitê editorial da Leonardo. Ela é uma perspicaz tradutora de culturas diferentes, atenta às barreiras sociais e econômicas que impedem o acesso à alfabetização digital. A preocupação com a comunicação entre culturas locais e globais é o tema de Private domain (please, keep off!), criado em meados dos anos 1990. Esse site on-line foi estruturado em torno dos problemas causados pela transição do uso dos caixas em bancos para as máquinas de atendimento automático. Em Private domain, Spitz empregou as formas populares de comunicação do Nordeste do Brasil. Os avatares que ela criou para os diferentes personagens desse domínio virtual são as figuras de barro folclóricas de retirantes nordestinos. Cada avatar, representando profissões e tipos sociais distintos, tem sua posição social descrita através de canções e poemas populares, assim como pela forma como se dirige - humildemente, educadamente, ou com uma voz de comando - às próprias máquinas de atendimento automático. Os diferente modos de dialogar com os terminais de computador expressam as tradicionais estruturas sociais do Nordeste, com a sutileza e o humor da linguagem coloquial. A distância entre esse domínio "privado", porque de impossível tradução, e a linguagem objetiva, fria e homogeneizante das máquinas de atendimento automático, nas mãos da artista, torna-se crítica do processo de globalização ao chamar a atenção para a riqueza das relações humanas que estão se extinguindo, e são a nossa perda:

Essa obra é sobre aquelas mãos vazias que estão na outra ponta da Internet. É sobre aquelas palavras que não podem ser traduzidas, sobre aquelas emoções que não podem ser partilhadas e aqueles significados que não podem ser compreendidos por pessoas de outras culturas. É sobre a riqueza dos seres humanos vivendo suas diferentes realidades, com seu próprio sistema de ideias, conceitos, regras e significados. ${ }^{37}$

A artista e curadora Suzete Venturelli, radicada em Brasília, também examina as relações sociais estruturadas no espaço virtual. Entre outros projetos, ela explora o mundo do videogame (Game art) através da construção de ambientes virtuais e avatares supersexy que, no mundo ficcional criado pela artista, subvertem os tradicionais papéis e expectativas de gênero. A perspectiva feminista de Venturelli, porém, não está voltada à desconstrução da violência inerente à indústria de videogames, mas a seu potencial criativo, uma vez que a artista considera a violência como parte central da psique humana, tanto masculina quanto feminina.

A artista e escritora Giselle Beiguelman, radicada em São Paulo, é autora de vários trabalhos, assim com de ensaios críticos/teóricos sobre as novas mídias on-line e seu impacto na vida contemporânea, na perspectiva da linguagem, do código e da arquitetura on-line. Beiguelman, cujo trabalho 
38. «www. canalcontemporaneo.

art.br> é reconhecido e premiado tanto no Brasil quanto no exterior, é, entre outras atividades, membro do comitê do programa internacional da ISEA - InterSociety for Electronic Arts. Desde 1996, ela é editora on-line da Arte/Cidade (uma organização sem fins lucrativos dedicada às artes e ao urbanismo) e, desde 1998, administra o site 〈www.desvirtual.com〉, um estúdio editorial e "bunker cibernético" onde ela mantém seus projetos criativos, tais como o premiado $O$ livro após o livro, um ensaio visual em hipertexto onde a crítica e a arte on-line combinam-se no contexto da leitura e escrita hipermídia.

Trabalhando também com a rede, mas radicada no Rio de Janeiro, a artista de mídia tática Patrícia Canetti é criadora e coordenadora do Canal contemporâneo - portal de arte na Internet mantido por assinatura. Canetti é ativista cultural e blogueira, e usa seu site on-line para hospedar e disseminar informações e discussões sobre arte contemporânea, assim como para mobilizar artistas com relação à formulação de políticas culturais nos níveis local e federal desde $2002^{38}$. O Canal contemporâneo tem sido eficaz desde seu início. Ele foi fundamental para organizar artistas no Rio de Janeiro e em outros lugares contra o uso de fundos públicos para construir uma filial do museu Guggenheim no Rio de Janeiro, assim como para garantir que as novas mídias fossem incluídas, nas novas leis federais para a cultura, no âmbito das artes visuais.

Não há nenhuma abordagem ou teoria feminista conectando os trabalhos das artistas midiáticas aqui abordadas, exceto uma postura crítica em relação à arte, à tecnologia e à cultura, essencial na produção e interpretação do conhecimento. Desde os primórdios da invenção da agricultura e da escrita, a vida vem sendo continuamente moldada e redefinida por novas tecnologias. A autorreflexão, a capacidade de fazer conexões e negociar com histórias e práticas heterogêneas - públicas e privadas, locais e globais - não é algo inerente às artes midiáticas exploradas por mulheres, é claro. Mas a qualidade do nosso futuro, das ecologias biofísicas às socioculturais, dependerá certamente da nossa capacidade de forjar um futuro mais igualitário, e ainda sim diverso.

Simone Osthoff, professora de estudos críticos na Pennsylvania State University, tem seus ensaios publicados em oito idiomas. É autora de Performing the archive: the transformation of the archive in contemporary art from repository of documents to art medium (Atropos, 2009). 